\title{
Will the Kyoto Protocol Affect Growth in Russia?
}

\author{
Franck Lecocq, ${ }^{*}$ Zmarak Shalizi \\ Development Economics Research Group, World Bank
}

\begin{abstract}
In light of the recent argument that rapid economic growth in Russia over the next decade might result in emissions higher than the Kyoto target, thereby putting muchneeded growth at risk, this paper revisits the discussion on the costs and benefits of ratification of the Kyoto Protocol by Russia. The paper concludes that even under a very high economic growth assumption, and even under very conservative assumptions about the decoupling between $\mathrm{CO}_{2}$ emissions and economic growth, Russia still benefits from a net surplus of emissions allowances, and thus will not see its growth adversely affected by the Kyoto target. In addition, a review of the possible costs and benefits of the Kyoto Protocol suggests that the potential sale of excess allowances far outweighs the other costs.
\end{abstract}

Keywords: climate change, Russia, economic growth, energy supply

JEL Classification: Q25, Q42, Q54, O52

World Bank Policy Research Working Paper 3454, November 2004

The Policy Research Working Paper Series disseminates the findings of work in progress to encourage the exchange of ideas about development issues. An objective of the series is to get the findings out quickly, even if the presentations are less than fully polished. The papers carry the names of the authors and should be cited accordingly. The findings, interpretations, and conclusions expressed in this paper are entirely those of the authors. They do not necessarily represent the view of the World Bank, its Executive Directors, or the countries they represent. Policy Research Working Papers are available online at http:/lecon.worldbank.org.

\footnotetext{
* Corresponding author: flecocq@worldbank.org. The authors would thank Tomoko Okano for her technical support in the preparation of this paper.
} 


\section{Introduction}

Over the past 14 years, Russia has been undergoing a massive transformation from a planned to a market economy. The transition was particularly painful by any measure: domestic gross product contracted by $39 \%{ }^{1}$ between 1990 and 1999, unemployment increased $27-$ fold $^{2}$, and a staggering $23.8 \%{ }^{3}$ of the population dropped below the $\$ 2$ a day poverty line (World Bank, 2004, IMF, 2004).

Since 1999, fueled by higher oil and gas exports, the Russian economy has started to move in the right direction again: the average growth rate has been $6.7 \%$ p.a. over the period 1999-2003. Yet Russia has barely recovered from the depression (its 2003 GDP has reached the level of 1992). As of 2003, 34 million people remained below the poverty line, and 1.6 million were unemployed (IMF, 2004).

In this context, it is perfectly legitimate to ask whether Russia's ratification of the Kyoto Protocol - which puts a cap on Russia's emissions of greenhouse gases (GHG) for the period 2008-2012 - could endanger growth in the short- and medium-term, given the fact that GHG emissions and economic growth usually move in the same direction. Is there a risk that business-as-usual emissions could exceed their 1990 target level in 2008-2012? And if that is the case, what would be the cost of meeting the target, and the impact on growth?

A large literature has been devoted to the first question, and the vast majority of the analyses find that Russia will gain a net surplus of emissions allowances - the so-called "hot air"-in the range of 300 to $1,000 \mathrm{MtCO}_{2}$ per year, on average, between 2008 and 2012 (Haites 2004). Thus, according to these studies, Russia will not lose, but will in fact gain from the Kyoto Protocol by selling part of its excess allowances to Europe, Japan and Canada. In this context, the economics of ratification boils down to whether or not Kyoto entails other costs that might counterbalance these benefits.

But the projection that the business-as-usual emissions of Russia will not exceed their target is not unanimously supported. An intriguing paper by the Russian Institute for Economic Analysis (IEAr, ${ }^{4}$ 2004) suggests that given the rigidities in the Russian economy, meeting President Putin's target of doubling the GDP in 10 years would generate emissions higher than the target between 2008 and 2012; as a result, Kyoto would become a binding constraint on Russia's economy.

The IEAr study differs from the other studies in two important assumptions: (i) it postulates, amongst different options, the highest economic growth rate over the next 10 years ( $7.2 \%$ against $2.9 \%-5 \%$ in the other studies), (ii) it uses the "carbon intensity" of GDP as a key parameter and assumes that this parameter will decline at a slow rate of less than $-2 \%$ p.a. This last assumption is justified using a set of "comparators". The IEAr analysis raises questions as to whether the results from the previous studies are

\footnotetext{
${ }^{1}$ Calculated using GDP in constant 1995 US\$

${ }^{2}$ 1991-1999

3 as of 2000

${ }^{4}$ We use the acronym IEAr for the Russian Institute for Economic Analysis to avoid any confusion with the International Energy Agency (IEA), whose work is also referenced in this paper.
} 
robust to higher economic growth rates, and as to whether the "comparators" method is valid.

The objective of the present paper is to review the debate on the costs and benefits of ratification of the Kyoto Protocol in light of the questions raised by the IEAr analysis. To do so, section 2 discusses whether Kyoto can constrain business-as-usual GHG emissions in Russia, even under the high economic growth rate scenario used in the IEAr study. Section 3 reviews the potential gains that Russia could get from selling excess allowances, and discusses whether hidden costs could offset them. Section 4 looks briefly beyond Kyoto, and section 5 concludes.

\section{Potential Costs to Russia Associated with Ratification of the Kyoto Protocol}

\subsection{Will Ratification of the Kyoto Protocol Constrain GDP Growth?}

The Kyoto Protocol imposes limits on the combined emissions of six gases $-\mathrm{CO}_{2}, \mathrm{CH}_{4}$, $\mathrm{N}_{2} \mathrm{O}$, HFCs, PFCs and $\mathrm{SF}_{6}$ - , the so-called "Kyoto gases", over the period 2008-2012, or first commitment period, for developed countries and transition economies, the so-called "Annex B" countries.

Russia is listed in the Annex B of the Protocol and, as such, is subject to a constraint on its GHG emissions for the period 2008-2012. The target for Russia is that its combined emissions of "Kyoto gases" should not exceed five times their combined 1990 levels during the period 2008-2012. This target is generally expressed in annual terms: on average, Russia's annual emissions of the six Kyoto gases should not exceed, their 1990 level—or 3,048 $\mathrm{MtCO}_{2} \mathrm{e}^{5}$ —over the period 2008-2012.

To meet their respective targets, member of Annex B, including Russia, can both adopt domestic policies and measures to reduce their emissions, and use three "flexibility mechanisms":

- Emissions trading, whereby an Annex B Party can purchase emissions allowances (or Assigned Amount Units, AAUs, in the Protocol's jargon) from another Annex B Party (Article 17 of the Kyoto Protocol).

- Joint Implementation (JI), whereby a Party of Annex B can participate in the financing of a project that reduces emissions in another Annex B country relative to what would have happened without the project, and use part of the emission reductions thus generated against its own target (Article 6).

- The Clean Development Mechanism (CDM), which is the same project-based mechanism as JI, but with the project located in a non-Annex B country.

In theory, the Kyoto Protocol could affect GDP growth in Russia in two ways: Since GHG emissions are in general related to economic activity, the constraint that the Kyoto Protocol puts on emissions could translate into a constraint on economic growth, either

\footnotetext{
${ }^{5}$ This is the official figure from Russia's Third National Communication to the UN Framework Convention on Climate Change (Government of Russia, 2002). The common unit for measuring emissions of the Kyoto gases are metric tonnes of $\mathrm{CO}_{2}$ equivalent $\left(\mathrm{tCO}_{2} \mathrm{e}\right)$.
} 
directly because Russia has to reduce its emissions, or devote resources to purchase emissions allowances through any of the three flexibility mechanisms to meet its Kyoto target, or indirectly because of Kyoto's impact on international energy markets and terms of trade.

As of 1999 - the last publicly-available estimate-Russia's combined emissions of the six Kyoto gases were 1,877 $\mathrm{MtCO}_{2} \mathrm{e}$, or 38.4\% below 1990 levels (Government of Russia, 2002), because Russia's GHG emissions declined sharply at the beginning of the 1990s with the ensuing economic crisis. $\mathrm{CO}_{2}$ emissions in 2003-the largest component of GHG emissions-were still only 1,589 $\mathrm{MtCO}_{2} \mathrm{e}$, or $32.7 \%$ below Russia's 1990 emissions of $\mathrm{CO}_{2}$ (InRU, 2004). ${ }^{6}$ It is thus not clear a priori that the constraint on emissions generated by the Kyoto Protocol will be binding. This subject is discussed in detail in subsection 2.2 .

Even if the GHG emissions constraint is not binding, the Kyoto Protocol could have indirect impacts on GDP growth in Russia via international markets for energy and carbon-intensive goods in general. For example, the Kyoto Protocol could reduce demand for oil and gas in Europe, Japan, and Canada, thereby reducing international prices, and affecting Russia's balance of trade; and by extension economic growth. Since Russia is a major exporter of oil and gas, this is a potentially important issue, which is discussed briefly in subsection 2.3 .

\subsection{Will There be a Direct Impact on GDP Through Binding Emissions Constraints?}

To determine whether the Kyoto constraint is binding, one needs to estimate what GHG emissions in Russia are likely to be in a "business-as-usual" scenario during the period 2008-2012. Obviously, GHG emissions over the next decade will depend on the underlying growth in GDP. The paper thus asks, under which assumptions for GDP growth would Russian GHG emissions be at risk of exceeding the Kyoto target? Since GHG emissions and GDP are in general positively correlated, the paper is particularly concerned with the high GDP growth rates scenarios.

This section first focuses on the link between GDP and $\mathrm{CO}_{2}$ emissions. There are three reasons for that. (i) $\mathrm{CO}_{2}$ is by far the most important gas in Russia's GHG emissions $\left(\mathrm{CO}_{2}\right.$ represented $80.4 \%$ of the combined emissions of "Kyoto gases" in 1999). (ii) $\mathrm{CO}_{2}$ emissions data is available up to 2003. And (iii) $\mathrm{CO}_{2}$ emissions originate mostly from the combustion of fossil-fuels to produce energy and heat (e.g., in coal- or gas-fired power plants or in trucks and cars). Since energy is a key production factor for industry, as well as a key service for households, studying the link between GDP and $\mathrm{CO}_{2}$ emissions makes a lot of sense.

Subsection 2.2.1 first reviews the econometric approach using aggregate data to analyze the link between GDP and $\mathrm{CO}_{2}$ emissions. It discusses, in particular, the econometric arguments underlying the IEAr (2004) finding that there will be only a slow decoupling between $\mathrm{CO}_{2}$ emissions and GDP in the coming decade. In 2.2.2, the paper reviews

\footnotetext{
${ }^{6}$ Institute of Energy Research (InRU) data are consistent with Gov. of Russia data for the period the series overlap.
} 
arguments based on less aggregated data that suggest the link between $\mathrm{CO}_{2}$ emissions and GDP is less rigid than the IEAr assumes. On this basis, subsection 2.2.3 finds that the Kyoto constraint is unlikely to be binding even for GDP growth rates corresponding to a doubling of GDP in 10 years (7.2\% p.a.). Lastly, subsection 2.2 .4 shows that this conclusion remains valid even when emissions from land use, land-use change and forestry are taken into account.

\subsubsection{Using an Econometric Approach to Estimate the Link Between $\mathrm{CO}_{2}$ Emissions and GDP with Aggregate Data}

Using cross-country panel data, several studies (e.g.., Heil and Selden, 2001, Ravallion et al., 2000) find a robust relationship between the level of GDP per capita and the level of $\mathrm{CO}_{2}$ emissions in the form of an inverse U-shaped curve. However, the robustness of this relationship at country level is controversial. For example, Moomaw and Unruh (1997) claim that observed peaks in emissions as GDP per capita increases are better explained by the two oil prices shocks than by increases in GDP per capita. This in turn casts doubt on the validity of the assumption that there is a "common development path" that all countries would follow, an assumption that is, however, necessary to use the U-shaped relationship between level of GDP per capita and level of $\mathrm{CO}_{2}$ emissions to project country-level emissions in the future (Heil and Segden, 2001). Instead, the focus should be on analyzing country-specific trends and parameters.

Cross-country panel data have also been used to estimate the relationship between the rate of growth of per capita GDP and the rate of growth of $\mathrm{CO}_{2}$ emissions. But no stable relationship emerges (e.g., Grubb, 2004).

The IEAr study (2004) sharply differs from the studies mentioned above. First, it focuses on the relationship between GDP per capita and the carbon intensity of GDP-that is the amount of carbon emitted per unit of GDP — rather than the elasticity of carbon emissions with respect to GDP. Second, it finds enough econometric evidence in past emissions trends to project that "the highest possible rates of decline in the carbon intensity of Russia's GDP [in the coming decade] are estimated at below 2.0 per cent per year." If that statement is true, it would significantly increase the likelihood that the Kyoto constraint becomes binding. It thus warrants careful examination.

\section{i) Principle Arguments and Conclusions in the IEAr Study}

To support its claim, the study offers four arguments based on past data - the first three are relationships between levels of GDP per capita and variations in carbon intensity, and the last is a relationship between the growth rate of GDP and the rate of change in carbon intensity:

a) The rapid decline in carbon intensity of GDP observed in Russia from 1998 to 2003 is an anomaly stemming in large part from favorable terms of trade. To project accurately over the next decade, one should either consider a longer period in the past (i.e. 1990-2003), or deduct terms of trade gains.

b) Countries that are better comparators for Russia have experienced lower rates of decline of carbon intensity of GDP in the past one to two decades.

c) Industrialized countries experienced low rates of decline of carbon intensity of GDP when their development in the past was comparable to Russia's today. 
d) High GDP growth rates are not correlated with high rates of decline in carbon intensity per unit of GDP. In fact, there are reasons to believe that high growth rates are correlated with low rates of decline.

In what follows, each of these arguments is analyzed in turn.

\section{ii) Principle Limitations of IEAr Arguments and Conclusions \\ a) Extrapolation from the longer post 1990 trend is not robust}

As acknowledged by the IEAr study, the carbon intensity of GDP in Russia's economy has not remained constant since 1990. In fact, it has followed an inverse U-shaped trajectory, increasing in the early 1990s, and decreasing steeply since 1998 (Figure 1).

As argued in the study, longer periods are in general superior to shorter ones to perform extrapolations. But the Russian economy has been undergoing significant transformation and adjustments in the last 12 to 14 years, so that even the 1990 to 2003 period does not provide meaningful parameters. In fact, within this longer period, the Russian economy experienced two sub-periods: a massive crisis in 1990-1997 - with a corresponding rise in carbon intensity, - which is unlikely to be repeated in the future, and a GDP growth rebound in the 1998-2003 period-which was accompanied by a decline in carbon intensity, - and is arguably more consistent with the assumptions made by the study that GDP growth will remain high in the period 2003-2012.

Figure 1: After an increase in the early 1990s, carbon intensity of GDP in Russia has decreased rapidly from 1998 to 2003

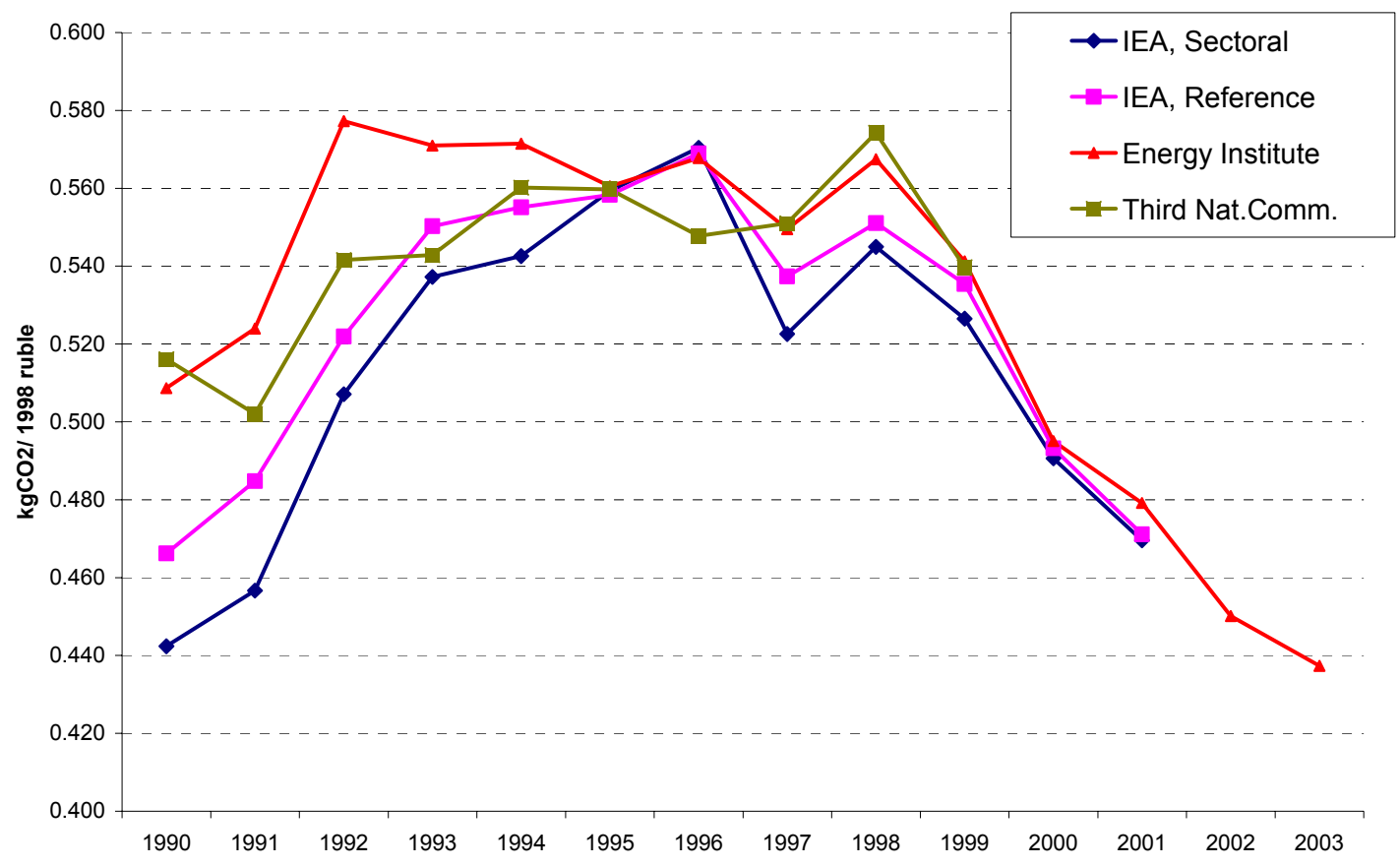

Source: WDI, 2004 (GDP), Gov. of Russia (2002), IEA, 2003a, InRU, $2004\left(\mathrm{CO}_{2}\right.$ emissions)

It is correct that - as argued in the IEA study - part of the GDP growth over the 19982003 period stems from favorable terms of trade. It is also unlikely, as noted in the study, that similar favorable movements in the terms of trade will occur again in the coming 
decade. This could superficially lead to an argument that the carbon intensity of unit GDP is not going to decline as rapidly in the future as it has in the recent past. However, by the same reasoning, there is a high probability that GDP growth rates in the future will not be as high as in the recent past without another round of favorable terms of trade movements, especially if there is reliance on existing capacity in the energy sector. If capacity in the energy sector is expanded to facilitate high GDP growth rates, it will be with more modern technology, as a result of which the carbon intensity of GDP will drop (see 2.2.2). More detailed inter-industry analysis is required to determine the net consequences of different investment and growth rates.

\section{b) The Comparators Used in the IEAr study are not Comparable}

The study argues that the relevant comparators for Russia are neither the rich countries in the industrial world today that show a strong decoupling between carbon emissions and GDP growth, nor the poorest countries at early stages of development where carbon emissions are growing sometimes faster than GDP. Instead, they argue that countries with similar per capita income levels and similar carbon intensities-the so-called "carbon intensive market economies below \$16,000 per capita GDP (PPP terms)"-are the appropriate comparators, and they show that the trendline of changes in carbon intensity for this set of countries is relatively low.

In fact, Russia stands out as an outlier in terms of carbon intensity to GDP even with respect to the members of this group (see taxonomy in the first table of the IEAr, 2004 study). As indicated in Table 1 below, the carbon intensity of GDP in Russia is nearly twice as high as the average carbon intensity of the GDP in the other countries in this group $\left(1.70 \mathrm{kgCO}_{2} / \$\right.$ against $0.91 \mathrm{kgCO}_{2} / \$, 2000$ data, PPP terms using $\$ 1995$, as per IEA, 2003a). 
Table 1: Russia is an outlier with respect to the study's own selected list of comparators: Russia's carbon intensity of GDP is twice as high as the comparators' average.

\begin{tabular}{lcc}
\hline Country & $\begin{array}{c}\text { Carbon Intensity of GDP } \\
\left(\mathrm{kgCO}_{2} / \$\right)\end{array}$ & $\begin{array}{c}\text { Per capita GDP in PPP } \\
\text { terms }(2,000, \text { using \$1995) }\end{array}$ \\
\hline Algeria & 0.38 & 5,000 \\
Venezuela & 1.01 & 5,171 \\
Zimbabwe & 0.44 & 2,372 \\
Jordan & 0.8 & 3,597 \\
Iran & 0.92 & 5,460 \\
South Korea & 0.64 & 13,945 \\
Lebanon & 0.84 & 3,866 \\
Libya & 1.42 & -- \\
Oman & 0.87 & 11,498 \\
Saudi Arabia & 1.03 & 11,716 \\
Syria & 1.09 & 3,067 \\
Trinidad and Tobago & 1.36 & 8,232 \\
South Africa & 0.69 & 8,702 \\
Jamaica & 1.14 & 3,370 \\
\hline Average of Russia's & 0.91 & $\mathbf{6 , 6 4 4}$ \\
Comparators & $\mathbf{1 . 7 0}$ & \\
\hline Russia & & $272-13,945$ \\
\hline \hline Sourc: & & \\
\hline
\end{tabular}

Source: IEA, 2003a

In addition, what is odd about this grouping is that the variation in per capita GDP is very high; from one half of that of Russia to double that. If we focus on countries with similar per capita incomes as Russia $(+/-\$ 1,000)$, then Russia stands out as an even larger outlier, by a factor of 4 .

Even if 10 to $15 \%$ of that difference can be accounted for by Russia's larger size and colder climate, there is a substantial inefficiency built-in to the observed high carbon intensity in Russia. This suggests that Russia is well inside the production frontier of market economies, while the other countries in the group-which have been functioning as market or quasi-market economies for much longer than Russia-are closer to the production frontier of market economies. Consequently, the trendline observed for other countries in the group are not relevant for Russia. 


\section{c) The carbon intensity trends of advanced economies at comparable stages of development as Russia are irrelevant}

The IEAr study draws from US and UK experience in the past century, which is totally meaningless given the amount of technological change since then and the availability of less carbon intensive technologies now.

\section{d) There is no robust statistical relationship between GDP growth rates and carbon intensity growth rates, either across countries, or over time within countries}

As the study recognizes, there is no statistically robust relationship between GDP growth and carbon intensity growth across countries, or over time. As noted in Dudek et al. (2004), there is also limited correlation between GDP growth rates and carbon intensity growth rates within a country over time. The claim that countries experiencing high growth rates are likely to experience lower than average rates of decline in carbon intensity is thus not supported by the facts.

\section{e) A General Limitation of the Econometric Approach: Future carbon intensity of GDP depends not only on structural variables, but also on policy decisions}

The arguments made by the authors of the IEAr study to justify a $-2 \%$ rate of decline in carbon intensity of GDP share a fundamental weakness with many other similar analyses in that the relationship between carbon emissions and GDP is treated as if it were exclusively determined by structural variables (such as climate, natural resources endowments, technological structure, exogenous innovation, per capita GDP, etc.) and not susceptible to policy interventions. Whereas in fact, policies will also have a strong impact on future carbon intensity of GDP. For example, the decision to increase, or not, domestic energy prices (for coal and gas) to reflect international price levels will have a strong influence on the carbon intensity in sectors of the economy that are sensitive to energy prices. Similarly, whether or not efforts are made to reduce existing inefficiencies in sectors that may not be currently sensitive to energy prices, such as in the production of electricity and heat (because of the prevalence of state-owned enterprises and weak budget constraints), will strongly affect the evolution of carbon intensity over the next decade.

In a mature economy on its production frontier, the policy component influences trends gradually and has an effect only over the long term. But in an economy inside its production frontier, with substantial inefficiencies, the effect of policy is likely to be more rapid. Hence one should be able to observe changes in carbon intensity in the short run as well. As already noted above, Russia is in the second category of countries rather than in the first.

Yet the IEAr study bases its statistical inferences on past emissions (which reflect both structural and policy decisions) without controlling for changes in policy variables. As a result, the capacity of the observed relationships to provide insights for next 10 years is doubtful. 


\subsubsection{Insights on Likely Trends in Carbon Intensity of GDP in Russia Using Less Aggregate Data}

\section{a) Carbon Intensity of GDP is Likely to Decline Faster than Assumed in the IEAr Study}

The discussion above casts doubt on the arguments put forward in the IEAr study to justify that carbon intensity of GDP will not decrease at a rate greater than $-2 \%$ per year over the next decade. The discussion above does not, however, provide a positive argument as to how carbon intensity might evolve in the future. Part of that argument is provided below.

The rate of variation of carbon intensity of GDP in Russia in the future probably lies somewhere between the $-2 \%$ per annum trend postulated in the study and the $-4.5 \%$ per annum trend experienced in the last five years based on actual data. Where is difficult to say without more work. That requires a different type of analysis using a computable general equilibrium model which builds in opportunities to reduce technical inefficiencies and improve price responsiveness, amongst other features.

As already pointed out, however, the structural inertia of the system is not as great as is implied in the IEAr study. There are three routes by which energy intensity of GDP can be reduced - all of which could have potentially significant impacts on Russia's carbon intensity of GDP (based in part on experience in other countries):

- A declining role of energy intensive sectors. This is relevant for Russia since a shift from a natural resource/energy intensive sectors to services and other less carbonintensive activities has been observed over the past decade (according to the World Development Indicators, the share of industry in GDP has decreased from $48 \%$ to $35 \%$ in the period 1990 to 2003 , while the share of services has risen from $35 \%$ to nearly $60 \%{ }^{7}$ ). The comparison with China is instructive: in 1990, China and Russia had similar carbon intensities of GDP: $1.35 \mathrm{kgCO}_{2} / \$$ and $1.51 \mathrm{kgCO}_{2} / \$$ respectively (GDP in PPP, 1995 dollars, as per IEA, 2003a). But in 2000, the carbon intensity of GDP in China was less than half of Russia's $\left(0.68 \mathrm{kgCO}_{2} / \$\right.$ against $\left.1.70 \mathrm{kgCO}_{2} / \$\right)$. The decision to diversify China's economy towards less energy-intensive manufacturing industry and services is central to that sharp divergence.

- An increase in the energy efficiency of energy-intensive activities. The Russian economy has one of the highest energy-intensities in the World, 2 times as high as in other transition economies, 2.3 times as high as in the U.S., 2.5 times as high as World average, and nearly 3.5 times as high as in the EU. ${ }^{8}$ And there is agreement among experts that Russia has a huge potential for energy efficiency gains. Golub et al. (1999), for example, evaluate this potential at $1 \mathrm{btCO}_{2}$ (at negative or zero abatement cost) in Russia. Another example is the leakage of fugitive methane from pipelines (see 2.2.3 below). The experience of other countries shows, as well, that programs to improve energy efficiency of energy-intensive industries can substantially reduce emissions per

\footnotetext{
${ }^{7}$ WDI (using GDP at factor cost)

${ }^{8}$ Based on 2002 data from the IEA Energy Balances for OECD and non-OECD countries, and the World Bank Development Indicators. GDP are expressed in PPP. Transition economies include Bulgaria, Croatia, the Czech Republic, Hungary, Poland, Romania, the Slovak Republic and Slovenia.
} 
unit of output. Japan, for example, adopted strong energy efficiency policies after the first oil shock, while South Korea did not. As a result, the energy-intensive industries in Japan became more productive. This is one of the reasons why carbon intensity, which was comparable to South Korea in $1971\left(0.60 \mathrm{kgCO}_{2} / \$\right.$ in Japan against $0.61 \mathrm{kgCO}_{2} / \$$ in Korea) is now half as high in Japan $\left(0.36 \mathrm{kgCO}_{2} / \$\right.$ against $0.65 \mathrm{kgCO}_{2} / \$$ in South Korea).

- A reduction in carbon emissions per unit of energy used through fuel switching. The experience of other countries suggests that the impact of these substitutions can be significant. For example, France had a carbon intensity one-third higher than Italy's in $1971\left(0.65 \mathrm{kgCO}_{2} / \$\right.$ against $\left.0.48 \mathrm{kgCO}_{2} / \$\right)$. In 2000 , the carbon intensity of GDP in France was $20 \%$ lower than Italy's $\left(0.27 \mathrm{kgCO}_{2} / \$\right.$ against $\left.0.34 \mathrm{kgCO}_{2} / \$\right)$, even as Italy's carbon intensity of GDP declined. The faster decrease in France is, for the most part, due to the policy decision in France, after the first oil shock, to invest in a massive nuclear generation program. The potential of fuel-switching in Russia is more controversial. In the short run, Grubb et al. (2004) point out that Russia already has a carbon intensity of primary energy ${ }^{9}$ close to that of the EU- $58.4 \mathrm{tCO}_{2} / \mathrm{TJ}$ in Russia against $51.3 \mathrm{tCO}_{2} / \mathrm{TJ}$ in the EU15 in 2001 (IEA, 2003a) - because of high reliance on gas, and because of the presence of nuclear. Yet according to the IEA (2002), new generation capacity will have to be installed to meet Russia's growing demand for electricity by 2010 , or even earlier if GDP growth rates are higher than the $2.9 \%$ p.a. that the IEA study postulates. ${ }^{10}$ The IEA estimates that this new capacity will be $90 \%$ gas. Such a substitution away from coal should lead to additional emission reductions. ${ }^{11}$

In transition economies where market forces are growing more rapidly than in Russia, a combination of these factors has led to a rapid reduction in carbon intensity (such as China, $-50 \%$, Poland, $-41 \%$ or the Czech Republic, $-26.1 \%$ between 1990 and 2001). In the future, similar improvements can be expected in Russia as, inter alia, (a) domestic prices of coal and gas move upwards, closer to international prices; and (b) as new capacity is installed, which relies on current technologies, which are more energy efficient than older technologies.

\section{b) A Proxy Model for Determining the Likely Rate of Decline in Carbon Intensity of GDP in a High-growth Scenario}

We have argued in the previous section that the arguments supporting a relatively rigid, high inertia energy economy with a $-2 \%$ annual rate of decline in carbon intensity of GDP put forward by the IEAr (2004) study are not valid, and that there are good reasons to believe that the relationship between GDP and $\mathrm{CO}_{2}$ emissions is less rigid - even over the next eight to ten years depending on the set of public policies that is adopted.

To project $\mathrm{CO}_{2}$ emissions in the future, the question is then as follows: will policies that tend to reduce carbon intensity of GDP be adopted? As noted by Mirrless-Black et al. (2004), some of these policies, such as liberalization of domestic energy prices, or

\footnotetext{
${ }^{9}$ The amount of $\mathrm{CO}_{2}$ emissions per unit of primary energy consumed.

${ }^{10}$ We will see below that $2.9 \%$ is in the lower end of the range of GDP growth projections for Russia in the coming decade.

${ }^{11}$ In the IEA (2003b) scenario, the share of coal in installed capacity decreases from $20 \%$ in 2000 to $15 \%$ in 2020 , while the share of gas increases from $42 \%$ to $57 \%$ over the same period.
} 
facilitation of domestic or foreign investment, are also prerequisites for higher growth. In other words, if one assumes a high GDP growth rate for Russia over the next decade, one must also assume for consistency that these policies will be adopted.

In the absence of a detailed model of the Russian energy sector and of the Russian economy, a qualitative way to analyze how the rate of variation in carbon intensity of GDP might vary with the rate of growth of per capita GDP is to use the IEA (2002) investment scenario mentioned earlier. Under this scenario, growth is sufficiently slow in the period 2001 to 2010 (2.9\% p.a.), that the bulk of the growth in electricity demand can be met by existing power generation capacity. Beyond 2010, however, that capacity will be exhausted, and new power generation capacity will have to be installed, mostly gas. Carbon intensity of GDP diminishes by only $0.8 \%$ p.a. for the first ten years, but then by $2.1 \%$ p.a. in the second decade as a large amount of new capital is invested and new capacity installed. In this scenario the economy almost doubles in 20 years (see Table 2).

Table 2: Assumptions of the IEA (2002) scenario for Russia

\begin{tabular}{|l|c|c|c|}
\hline & $\mathbf{2 0 0 0}$ & $\mathbf{2 0 1 0}$ & $\mathbf{2 0 2 0}$ \\
\hline GDP (b\$ 1995) & 428.5 & 570.3 & 804.5 \\
\hline $\begin{array}{l}\text { CO2 Emissions } \\
\left(\mathrm{MtCO}_{2} \text { p.a.) }\right.\end{array}$ & 1,492 & 1,829 & 2,068 \\
\hline $\begin{array}{l}\text { Carbon Intensity of } \\
\text { GDP (kgCO } / \text { } \text { ) }\end{array}$ & 3.48 & 3.20 & 2.57 \\
\hline $\begin{array}{l}\text { Coal in Electricity } \\
\text { Mix (TWh) }\end{array}$ & 176 & 213 & 213 \\
\hline $\begin{array}{l}\text { Oil in Electricity Mix } \\
\text { (TWh) }\end{array}$ & 33 & 33 & 27 \\
\hline $\begin{array}{l}\text { Gas in Electricity } \\
\text { Mix (TWh) }\end{array}$ & 370 & 334 & 358 \\
\hline $\begin{array}{l}\text { Others in Electricity } \\
\text { Mix (TWh) }\end{array}$ & 298 & & \\
\hline
\end{tabular}

If the target of doubling GDP in 10 years put forth by Mr. Putin and included as the high case in the IEAr study is assumed (7.2\% economic growth p.a.), that is equivalent to compressing the IEA economic growth projection into a 9-year period instead of a 20year period. But such accelerated growth in GDP will have to be accompanied by accelerated growth in electricity demand, exhausting existing capacity and requiring new investment, so it can be assumed that the evolution of the energy system described in the IEA (2002) scenario would also take place in 9 years instead of in 20 years. As a result, the carbon intensity of GDP would decline from 3.48 to 2.57 in 9 years, at an average of $-3.3 \% /$ rate p.a. 


\subsubsection{Is the Kyoto Target Binding or Will There be a Surplus of Allowances? \\ a) The Share of Non-COO Gases Emissions will not Increase}

Non- $\mathrm{CO}_{2}$ GHG emissions have been declining at an even more rapid rate than $\mathrm{CO}_{2}$ emissions during the past decade. In 1990 , non- $\mathrm{CO}_{2}$ emissions amounted to $22.6 \%$ of total GHG emissions. In 1999, this share had decreased to $19.6 \%$ (Gov. of Russia, 2002).

As of 1999, fugitive methane emissions from leaks in gas pipelines still accounted for the majority of non- $\mathrm{CO}_{2}$ emissions (54\%). Yet they have diminished substantially since 1990 , and a program adopted by Gazprom aims at reducing them by a further half between 2000 and 2012 (UNFCCC, 2004, pp.16-17).

Thus, it is likely that the share of non- $\mathrm{CO}_{2}$ emissions will continue to diminish through 2012. However, a conservative assumption is to assume that this share will remain constant from 1999 to 2012.

Figure 2: GDP, $\mathrm{CO}_{2}$ emissions and non- $\mathrm{CO}_{2}$ emissions 1990-2003

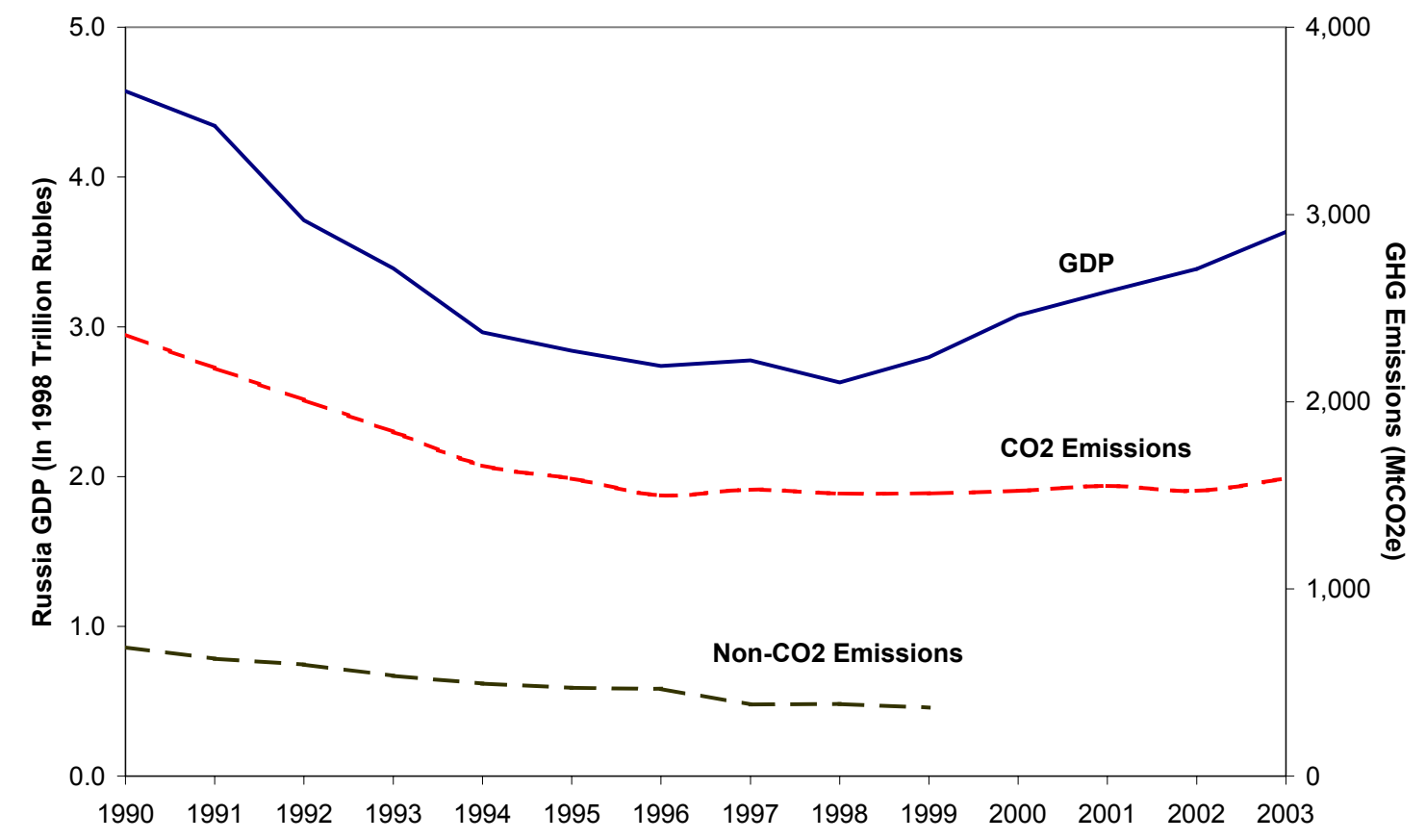

Source: Gov. of Russia, 2002 and InRU, 2004 for emissions, World Bank Development Indicators, 2004 for GDP.

\section{b) Combined GHG Emissions Projections}

Based on the discussion in 2.2.2, is it likely that (i) the carbon intensity of GDP will be a function of the rate of growth of GDP growth, and that (ii) carbon intensity will decrease a rate largely below than $-2 \%$ p.a. for high GDP growth rates (around 6-7\% p.a.). In Table 3 below, we assume two scenarios for the carbon intensity of GDP, namely that it decreases either by $-2 \%$ p.a. or by $-4 \%$ p.a. And we assume two scenarios for GDP growth rates: namely $7.2 \%$ p.a. and $4 \%$ p.a. (as in Mirrless-Black et al., 2004). We still 
leave the combination $(-2 \%, 7.2 \%)$, although it is not likely given the discussion above. Similarly, the combination $(-4 \%, 4 \%)$ is also unlikely.

Table 3: Annual average GHG Emissions (in MtCO2e) and total surplus of emissions allowances over the period 2008-2012 under two GDP Growth Rates assumptions, and two carbon intensity decrease rates assumptions - assuming that the share of non- $\mathrm{CO}_{2}$ gases in total GHG emissions remains constant between 1999 and 2012

\begin{tabular}{|c|c|c|c|}
\hline & & \multicolumn{2}{|c|}{ Rate of Decline of Carbon Intensity in GDP } \\
\hline & & $\mathbf{- 2 \%}$ & $\mathbf{- 4 \%}$ \\
\hline \multirow{2}{*}{\begin{tabular}{c}
$*$ \\
\hdashline
\end{tabular}} & $\mathbf{7 . 2 \%}$ & $2,825(1,115)$ & $2,466(2,910)$ \\
\cline { 2 - 4 } & $\mathbf{4 \%}$ & $2,271(3,884)$ & $1,976(5,360)$ \\
\hline
\end{tabular}

Source: Authors' calculation

Table 3 shows that even under the most conservative set of assumptions - a 7.2\% GDP growth rate from 2003 to 2012 , a slow rate of decrease of carbon intensity of GDP (-2\% p.a.), and a non-declining share of non- $\mathrm{CO}_{2}$ gases in total emissions-average $\mathrm{GHG}$ emissions over the period 2008-2012 are below the 1990 level $\left(2,825 \mathrm{MtCO}_{2} \mathrm{e}\right.$ against $\left.3,048 \mathrm{MtCO}_{2} \mathrm{e}\right){ }^{12}$ In other words, even in this very conservative case, the Kyoto Protocol does not constrain Russia's emissions or GDP growth rate. In fact, even in this set of assumptions, Russia has a net surplus of emissions allowances of $1,115 \mathrm{MtCO}_{2} \mathrm{e}$ over the commitment period. ${ }^{13}$ Table 3 also shows that for less conservative assumptions about GDP growth rate and rate of decline of carbon intensity in GDP, the annual average emissions between 2008 and 2012 is lower, and the total amount of surplus allowances is higher.

\footnotetext{
${ }^{12}$ In most cases, projected GHG emissions never exceed 1990 levels from 2008 to 2012. It is only for a growth rate of $7.2 \%$ per year and a carbon intensity of GDP decreasing at only $-2 \%$ p.a. that GHG emissions exceed 1990 levels in 2012. But even in that case, on average, GHG emissions between 2008 and 2012 remain below the Kyoto target.

${ }^{13}$ This result differs from IEAr (2004) for three reasons.
}

- $\quad$ First, the IEAr study assumes that $\mathrm{CO}_{2}$ emissions from fossil-fuel are $1,633 \mathrm{MtCO}_{2}$ in 2003. However, it is not clear where this figure comes from. 2004 emissions data from the Energy Institute of the Russian Academy of Science suggests that 2003 emissions were in fact 1589 $\mathrm{MtCO}_{2}$, or $44 \mathrm{MtCO}_{2}$ less. Although the Energy Institute data is not official emissions data, it is fully consistent with official emissions data for the period they overlap

- Second, IEAr (2004) uses data from IEA (2003a) for $1990 \mathrm{CO}_{2}$ emissions. However, the proper $1990 \mathrm{CO}_{2}$ emissions level that should be used to set the target is the one given in Russia's Third National Communication to the UNFCCC $\left(2,360 \mathrm{MtCO}_{2}\right)$, and not the level reported by the International Energy Agency that is used in the study (,2023 $\mathrm{MtCO}_{2}$, as per IEA, 2003a, sectoral approach). The reason is that the former is based on the IPCC methodology, while the latter is not (IEA, 2003a, pp.xliv-xlv); and that inventories to the UNFCCC and the Kyoto Protocol must follow IPCC guidelines.

- Third, IEAr (2004) does not account for the fact that the share of non- $\mathrm{CO}_{2}$ gases in Russia's GHG emissions has decreased significantly from 1990 to 1999. 


\subsubsection{Can Emissions Related to Land Use, Land-Use Change or Forestry Offset the Surplus of Allowances?}

\section{a) Emissions from land-use changes under Article 3.3 of the Kyoto Protocol are Unlikely to Offset Net Surplus of Allowances}

Under Article 3.3 of the Kyoto Protocol, Russia must account for the carbon uptakes and releases from the areas which have been afforested, reforested or deforested since 1990. Russia would thus only be liable for significant emissions from land-use change under the Protocol if it were to practice large-scale deforestation, which is not the case at present. In fact, the carbon stock and area of Russia's forest has been growing in the past decades (Schvidenko and Nilsson, 2002).

In addition, once an area is registered under Article 3.3 (because it is either afforested, reforested or deforested), the amount of carbon stocked on this area continues to be monitored. Thus, if there is a forest fire in plantations established since 1990, the stored carbon would be lost, and there would be a debit under Article 3.3. However, the areas where new plantations are established are relatively small, with limited carbon stock per hectare, as the trees are still young. In addition, these plantations are managed to reduce the risk of forest fires. As a result, regeneration in the forests which are expanding will likely more than offset losses due to forest fires.

\section{b) The surplus of allowances could increase from provisions of Article 3.4 of the Kyoto Protocol, but not necessarily}

Under Article 3.4 of the Protocol, Russia has the option (but not the obligation) to designate standing forests under "forest management" and account for changes in their stock of carbon. There is an incentive for Russia to do so because- under the Marrakech Accords - it can claim up to $120 \mathrm{MtCO}_{2} \mathrm{e}$ under this option. And Russia has more than enough forest to meet this requirement since its forests, overall, are currently storing carbon at a rate of about $800 \mathrm{MtCO}_{2} \mathrm{e}$ per year.

Some analysts (e.g., Dudek et al., 2004) have presented these $120 \mathrm{MtCO}_{2} \mathrm{e}$ as an additional emissions budget for Russia, on the implicit assumption that designating forests under forest management bears little or no costs. However, by electing to claim for forest management, Russia would also become exposed to the risk of losses from fires in the forests it designates. The carbon content per hectare of forests managed under Article 3.4 might be higher than that of the plantations covered under Article 3.3, because forests under management under Article 3.4 are likely to be older. In addition, whereas plantations are managed to reduce the risk of fires, non-plantation forests in Russia are poorly protected against this risk. In fact, forest fires are currently responsible for emissions between 150 to $300 \mathrm{MtCO}_{2} \mathrm{e}$ per year. This risk could arguably increase over time as global warming is accompanied by drier conditions, unless policies are put in place to dramatically improve monitoring and rapid response to forest fires, as in Brazil, and contrary to Indonesia (World Bank, 2001).

In summary, the claim that Russia could simply add, up to $120 \mathrm{MtCO}_{2} \mathrm{e}$, to its Kyoto target at no costs because of Article 3.4 is incorrect. The options opened up by Article 3.4 are potentially of genuine interest to Russia, but the costs and benefits of using them need to be assessed more carefully. Then again, this is a decision that is totally separate from 
the ratification decision. Neither Russia, nor any other Annex I country for that matter, is obliged to make it now.

\subsection{Will There be an Indirect Impact on GDP Through International Energy Markets and the Terms of Trade?}

The previous section has demonstrated that even under very conservative assumptions regarding the evolution of carbon intensity of GDP, and very high assumptions regarding economic growth rates, the Kyoto target would not be binding, and thus would not directly constrain economic growth in Russia.

Yet growth in Russia could be indirectly affected by changes that Kyoto might induce in international markets - such as oil and gas markets - and thus through changes in the terms of trade. This is of special importance to Russia since it is a major exporter of oil and gas, and revenues from these exports amount to $6.2 \%$ of GDP.

The logic is as follows. In Annex I countries (without the U.S. and Australia), the Kyoto Protocol is likely to induce conservation efforts as well as shifts towards less carbonintensive energy sources (from coal to gas and from gas to renewables). The net effect of this adjustment is likely to be a lower demand for oil, and maybe for gas. As a result, international prices of oil, and possibly gas, might decline slightly.

There has been surprisingly little research on the impact of the Kyoto Protocol on international energy markets since the decision of the U.S. to withdraw from the Protocol. Most of the figures available in the literature thus relate to a scenario in which the U.S. participates, thus overestimating the real impacts of the Protocol. For example, Holtsmark and Maestad (2001) estimate that the international price of oil in 2010 would be reduced by $2 \%$ relative to what it would be otherwise, and that the international price of gas in Europe would be reduced by $4 \%$ compared to what would have happened otherwise with U.S. participation. It is likely that the figures would be lower without the U.S., since the global constraint on emissions is then much lower.

Holtsmark (2003) argues that without the U.S. the Kyoto Protocol results in a maximum $-0.75 \%$ decrease in the international price of gas and a maximum $-1.0 \%$ decrease in the price of oil. Holtsmark also points out that the impact of Kyoto on the international energy markets are not independent of the amount of carbon that Russia sells. In fact, the domestic mitigation efforts in Europe, Japan, New Zealand and Canada depends on the amount of allowances Russia sells. The domestic constraint on Europe, Japan, New Zealand and Canada can even go down to zero if Russia sells a sufficient amount of allowances (see details in section 3 below). Yet selling large amount of allowances also depresses the price of allowances, and thus reduces the net proceeds from the sale. As a result, there is a trade-off between selling more credits and reducing the impact of Kyoto on the energy markets at the expense of the price of carbon itself, and selling fewer allowances to maximize the benefits from the sale of allowances, but at the expense of lower revenues from oil and gas exports. Hotlsmark (2003) suggests that Russia's optimal strategy is probably to sell more rather than less.

Leaving this trade-off aside, and assuming the worst impacts of the Kyoto Protocol on energy markets mentioned above, what would be the impacts on Russian growth? The impact would be twofold. First, reduced proceeds from the international sale of oil and 
gas (as assumed by Holtsmark, 2003) would effect the trade balance and therefore GDP. Second, reduced exports could reduce domestic investment capacity, and therefore limit growth. Estimates of the sensitivity of GDP growth to oil prices reported in MirrlessBlack et al. (2004) range from $0.07 \%$ to $0.08 \%$ decrease in GDP growth per percent increase in international oil prices. According to these figures, the $1 \%$ decrease in oil prices noted above would reduce Russia's GDP growth rate by less than $0.1 \%$. A more detailed macroeconomic model of the Russian economy, however, would be necessary to produce a more accurate number.

\section{Potential Benefits to Russia Associated with Ratification of the Kyoto Protocol}

\subsection{Can Ratification Benefit the Russian Economy?}

So far, this paper has focused on the potential costs of the ratification of the Kyoto Protocol by Russia in terms of potential growth foregone, and it has concluded there are none even in worst case scenarios. However, Russia can also benefit from the Kyoto Protocol in two ways:

- First, as discussed in section 2, Russia GHG emissions in 2008-2012 are very likely to be below the Kyoto target. Russia can either sell these AAUs at no cost to its economy, or bank them for future commitment periods.

- Second, many believe that the Russian economy has a large supply of low-cost mitigation options. As long as domestic mitigation costs are lower than the international price of emission allowances, Russia can exercise these options, and either sell further AAUs than the excess ones under international emissions trading, or sell Emission Reduction Units under Joint Implementation (Article 6 of the Kyoto Protocol) for a profit.

To evaluate the potential benefits associated with each option, it is necessary to evaluate the potential supply and demand for AAUs on the international market, as well as the potential price for AAUs (sub-section 3.2). On this basis, subsection 3.3 discusses the potential benefits of the sale of "excess" AAUs, and subsection 3.4 the sale of emission reductions beyond the excess AAUs, via either JI or emissions trading.

\subsection{What Might the Carbon Market for AAUs Look Like in 2008-2012?}

\subsubsection{A Two Stage Process for Determining the Volume of AAU Sales}

The combined emissions of the EU, Canada, Japan, and other industrialized countries members of Annex I are expected to exceed their combined Kyoto targets by 5,000 to 5,500 $\mathrm{MtCO}_{2} \mathrm{e}$ during the first commitment period, given their current emissions levels, and assuming business-as-usual emissions growth over the next decade. ${ }^{14}$ To meet this potential shortfall, these countries can either implement more policies and measures to reduce domestic emissions, or they can purchase credits through CDM and JI projects, or

\footnotetext{
${ }^{14}$ Based on emissions data (all gases) from 2001 on UNFCCC website. Emissions growth rate from 2001 to 2010 extracted from IEA (2003b) and U.S. DoE (2003).
} 
through international trading of allowances. Russia could be a suppler in the latter two cases.

Most of the models of the carbon market to date assume that countries decide to allocate their resources all at once, and that the markets for JI, the CDM and AAUs all clear simultaneously. In reality though, these markets are likely to be solved sequentially. The reason is that project-based transactions, such as JI or the CDM, involve substantial lead times between the moment the project is prepared, and the moment it actually starts operating and "yielding" its first emission reductions - typically 5 to 7 years for energy projects. As a result, the window of opportunity for starting projects that will generate emission reductions by 2012 is actually closing rapidly.

The same can be said about domestic policies and measures. The time lag between the conception and the enactment of a law can be several years. And the benefits of the law in terms of reduced emissions might also be felt only in a gradual way, especially since OECD governments have only indirect control over major sources of domestic emissions, such as transportation, industry or even energy. As a result, we depart from the assumption that the inter-linked carbon markets will clear simultaneously. More likely, governments will first make their choices about domestic policies and purchases of JI and CDM allowances. Then the remaining supply and demand is cleared on the spot AAU allowance market.

\subsubsection{Potential Demand for AAUs (Net of Domestic Policies, Supply of JI and the CDM)}

It is difficult to estimate how much can and will be done domestically by Europe, Canada, Japan and New Zealand beyond what is already included in the projections mentioned above. A review of models by Haites (2004) shows a net demand for AAUs between 3,000 and 5,500 $\mathrm{MtCO}_{2} \mathrm{e}$. Domestic projections included in National Communications to the UNFCCC yield a combined shortfall of $2.5 \mathrm{btCO}_{2} \mathrm{e}$. Presumably, this low figure stems from the fact that national communications include more domestic policies and measures than other models. We choose this figure as a conservative low estimate of the potential demand for emission reductions by Annex B countriesdomestic policies and measures included.

Since the CDM is expected to supply between 300 and $500 \mathrm{MtCO}_{2} \mathrm{e}$ (Haites, 2004), the potential total demand for AAUs from Russia and other economies in transition could be around 2,000 to 2,500 $\mathrm{MtCO}_{2} \mathrm{e}$.

\subsubsection{Potential Supply of AAUs}

Table 3 indicates that Russia's total amount of excess AAUs might be between 1,115 and 5,360 $\mathrm{MtCO}_{2} \mathrm{e}$ over 2008-2012. But as argued in section 2 the two extreme boundaries (in shaded grey in Table 3) have much lower probability. Realistically, Russia's total amount of excess AAUs might thus be between 2,900 and 3,900 $\mathrm{MtCO}_{2} \mathrm{e}$.

In addition, Ukraine and all other transition economies could have between 2,500 and 3,500 $\mathrm{MtCO}_{2} \mathrm{e}$ for sale. In other words, Russia might represent a little more than half of total supply of excess AAUs, with Ukraine accounting for about one fourth, and all other transition economies the remaining fourth. 
Thus, there is a large imbalance between potential supply and potential demand of AAUs, especially if we assume that OECD countries meet half of the gap between their businessas-usual emissions and their Kyoto targets through domestic policy reforms and measures. In this case, the supply of excess allowances could be between two and three times as large as demand.

This means that Russia will not be able to sell all its excess allowances. Keeping some AAUs, however, has advantages for Russia, and should certainly be part of its portfolio. First, the Kyoto Protocol allows for keeping AAUs for use in future commitment periods (banking). This provides value even to the allowances that are not sold. In addition, this reserve could act as an insurance against any risk, however remote, that Russia's emissions might overshoot its target.

How much Russia is able to sell will depend on the competition from Ukraine and other transition economies, as well as on the preferences of buyer countries. Although Ukraine and other transition economies could in theory supply all the $2,500 \mathrm{MtCO}_{2} \mathrm{e}$ required by countries in need of allowances, this scenario has a low probability of occurrence for several reasons. First, it would require Ukraine and other transition economies to keep very low or zero buffers against unexpected high GDP growth rates in their own countries. Second, it would mean that Ukraine is able to attract large-scale investments, which is not the case at the moment. Third, it would mean that OECD countries are bypassing Russia, the largest economy in the region, which also seems rather unlikely.

For these reasons it is more likely that Russia could sell about $1,000 \mathrm{MtCO}_{2} \mathrm{e}$ on the international market. This amount is less than Russia's share in the Protocol, but it is consistent with results of modeling exercises compiled by Haites (2004), in which Russia never sees less than $1,250 \mathrm{MtCO}_{2} \mathrm{e}$ over the first commitment period.

\subsubsection{Potential Price for AAUs}

Current prices of certified emission reductions under the CDM are between $\$ 3$ and $\$ 6$ per $\mathrm{tCO}_{2} \mathrm{e}$. Prices on the emerging allowance markets are higher (around $€ 8-9 / \mathrm{tCO}_{2} \mathrm{e}$ per $\mathrm{tCO}_{2} \mathrm{e}$ for EU allowances as of October 2004).

It is difficult to predict prices of allowances during the first commitment period. In a purely competitive market, excess supply should lead to a price of zero. However, as noted above, Russia and to a lesser degree Ukraine have strong market power and do not need to sell all their allowances. Prices are all the more difficult to predict given that AAU purchases are likely be part of larger arrangements that might involve, for example, oil and gas exports from Russia, as well as investments in the energy sector.

Willingness to pay by buyers is also difficult to evaluate. Surveys reveal that most market players are anticipating a price of allowances around $\$ 10 / \mathrm{tCO}_{2} \mathrm{e}$ during the first commitment period. This is consistent with current prices of European allowances, as well as with what governments are currently willing to pay for JI or CDM transactions (nominal prices per tonne are lower under these two mechanisms because risks are higher than with AAU allowance purchases). Yet absent any other data, the projections below are based on a conservative price of $\$ 6 / \mathrm{tCO}_{2} \mathrm{e}$, the higher range of current prices for certified emission reductions. 


\subsection{Potential Barriers to Sale of Excess Allowances can be Overcome by "Greening" of the Allowances}

Under the price and quantity assumptions outlined above, Russia could conservatively expect at least $\$ 6$ billion in direct revenues from the sale of excess AAUs over the period 2008-2012. However, realizing this potential might face significant barriers as some OECD Parties have expressed reluctance to buy excess AAUs or "hot air".

From a legal point of view, there is no distinction between "excess" allowances-that is allowances beyond the country's baseline emissions - and "normal" allowances. In fact, it is very difficult to distinguish between them ex ante, because trading will take place before the emissions are measured (emissions inventories are typically available with a 1 to 2 years delay), and thus, before one really knows whether AAUs are "normal" or "in excess".

Yet from a political economy point of view, buying what has been dubbed as "paper tonnes" might not be palatable to the public opinions in a number of countries. As a result, major stakeholders, governments and firms are under pressure not to purchase "hot air" (Koch and Michaelowa, 1999). But too high a price for carbon is equally unacceptable to governments and firms, thus foreclosing the possibility to tap into the "hot air" reserve is also a difficult decision to make.

Hence the idea of "greening" AAUs, that is to somehow tie part of the revenues from the sale of "excess" AAUs to activities beneficial to the environment. By ensuring the environmental integrity of the AAUs, greening enables AAU buyers to be politically correct, and increases demand for AAU sellers. In fact, the government of Canada and some EU member countries have announced that they do not intend to purchase "hot air" unless it is somehow "greened."

Greening links the sale of AAUs with an underlying project or set of projects. As a result, the project is likely to become more attractive because it has another product to sell (namely AAUs), thus increasing its internal rate of return. In addition, the AAU purchase contract might have high value for financing institutions because it is denominated in strong currency (e.g., euros or dollars), and consists of buyers with strong credit ratings (most probably sovereigns). Lastly, if AAU delivery and payment is somehow tied to project performance, this builds confidence in the other investors that the project is sound.

To maximize this leverage effect, Russia could for example create an "AAU Fund". The fund would pool money from private and public entities to buy AAUs. This would attract capital for financing the underlying projects. This money-which could be supported by bilaterals and multilaterals, for example in the form of partial risk guarantees-would

\footnotetext{
${ }^{15}$ Canada Climate Change Plan (2002) states that "One issue that has received considerable attention is the possibility of buying surplus permits from Russia and eastern European countries, where economic decline over the past decade has lowered their emissions below their Kyoto target. The Government of Canada has already indicated that it would buy such permits only if the selling country agrees to invest the proceeds from the sale in projects and activities that contribute to emissions reductions. This is called 'greening' surplus permits and ensures that these purchases result in real environmental benefits that contribute to addressing climate change." (p.43)
} 
then fund projects in the energy sector in Russia. As the projects perform, AAUs would be delivered against payments.

It is expected that such a fund could attract about 3 times, and possibly as high as 5 times, as much capital as the amount required for AAU purchases. The total amount of capital that could be leveraged could thus be, conservatively, on the order of $\$ 24 b$ to $\$ 36 b$ during the five years of the first commitment period. This is not an insignificant amount. The IEA (2003b) estimates that Russia will need about $\$ 17 \mathrm{~b}$ of investment in the energy sector annually over the period 2001-2010 to tap its vast oil and gas resources, fuel its economic growth, and serve foreign markets. Likewise, huge investments are needed to maintain and extend the transportation infrastructure, as well as provide housing. Yet gross domestic fixed capital formation is not sufficient to meet the large investment demand and net annual inflows of Foreign Direct Investment have been a meager $\$ 2 b$ to $\$ 3.5 \mathrm{~b}$ in recent years.

\subsection{Joint Implementation and the Sale of AAUs Beyond "Excess" Allowances}

In addition to selling "excess" AAUs - at no economic cost to the Russian economyRussia may also be able to sell Emission Reduction Units under Joint Implementation. In practice, the discussion in section 3.2.3 suggests that it is unlikely that the demand for AAUs will be high enough to justify Russia using this option.

However, there may well be joint implementation opportunities in the country, that could substitute for the sale of AAUs. Using JI might be beneficial for Russia because the costs of reducing emissions for the JI project should be lower than the price paid for the emission reductions, and because this saves more allowances to be banked for future periods. However, it is unlikely that the number of JI projects will be very large because of the time-lag constraint that also affects the CDM.

\section{Impacts Beyond 2012}

\subsection{Does the Kyoto Protocol Entail Any Cost to Russia Beyond 2012?}

In several instances throughout the IEAr (2004) study, it is implied that by ratifying the Kyoto Protocol, Russia (i) also accepts targets beyond the first commitment period, and (ii) that these targets are likely to impose severe restrictions on the country's emissions and growth.

Both statements are wrong. The Kyoto Protocol has no provision for allocating quotas beyond 2012; nor does it obligate Russia in any way vis-à-vis the international climate regimes that might come beyond Kyoto. In other words, Russia does not take on any commitment beyond 2012 by ratifying the Kyoto Protocol.

Moreover, the international climate regime beyond 2012 will be negotiated by the Parties to the UNFCCC, which include Russia. Russia will thus have its say in the negotiations, and will have, as any other Party, the right to accept or reject the compromise that comes out of these negotiations. 
However, independently of Kyoto, Russia as a member of the community of Nations will have to participate in finding ways to effectively and fairly deal with global warming as a global public good.

\subsection{Kyoto Ratification and Long-Term Climate Change}

The argument has been made that Russia might be a net beneficiary of climate change, at least if climate change remains within reasonable margins. As a result, it might be in the national interest of Russia to, in fact, limit action on climate change.

Unfortunately, given the current state of knowledge about the potential impacts of climate change, it is not clear that Russia belongs to the camp of the "winners" of climate change. In fact, there is sufficient uncertainty on the scale and direction of different impacts that it would be a big risk to assume that, net, Russia could be better off.

In northern zones, some estimates indicate that agricultural productivity could increase as a result of warmer, longer growing seasons. But the extensive agricultural regions of southern Russia are largely semi-arid zones. These are expected to experience increased drying, especially during the growing season. Even if agriculture in Russia overall could benefit, there could still be a large number of losers.

These estimates for agriculture are also based only on an increase in average mean temperature. But as Russia experiences disproportionately large warming in comparison to the rest of the world (Houghton et al., 2001), the hydrologic cycle is likely to intensify, causing more intense rainstorms, snowstorms and more flooding, requiring massive physical investment to protect against these hazards. ${ }^{16}$

In other sectors, climate change might also cause severe damages. In the transport and energy sectors for example, melting of permafrost in the Arctic will damage much of the buildings, transport infrastructure, and installations for oil and gas extraction, that are built on top of permafrost (e.g., Anisimov, 1997). In addition, Russia has a gigantic coastline. As sea level rises, coastal areas will suffer from increased storm damages and flooding, again requiring massive physical investment just to protect existing infrastructure and maintain existing levels of welfare, at the expense of developing new infrastructure and improving welfare.

Lastly, neither Russia - nor any other country for that matter-can consider only the climate change damages that affect its own territory. In the regions hit hardest, climate change might indeed trigger international spillovers such as changes in international markets, migrations, or conflicts over scarce resources (e.g., water). Should warming significantly degrade livelihoods south of the Russian border (e.g. in North-East China, Mongolia, or the Republics of Central Asia), it is possible that migratory pressure on the large and relatively low-density territory of Russia could increase significantly.

\footnotetext{
${ }^{16}$ These hazards exclude ecosystem and biodiversity damages which also could be quite serious. Climate change may result in extinction of certain animal and plant species. As rates of warming increase, it is likely that many species will be trapped, because the change will be too fast, and there will be too many human obstacles in their path to allow these species to move to more suitable locations and adapt successfully to the changing climate. And some arctic species such as polar bears, reindeer, and Arctic foxes may have nowhere to go at all.
} 
The discussion above does not attempt to exhaust the subject, but to highlight the uncertainty intrinsic to the evaluation of the impacts of climate change. As a result, there is currently no certainty that Russia could benefit, overall, from climate change.

\section{Conclusion}

This review of the potential consequences of ratification for Russia concludes that contrary to the implication in the IEAr (2004) study - it is highly unlikely that ratification

of the Kyoto Protocol will reduce economic growth in Russia, either directly by curtailing its GHG emissions, or indirectly through international energy markets. On the other hand, ratification is likely to benefit Russia by allowing for the sale of some AAUs, and associated investments especially if "green investment schemes" are set up.

Given the uncertainty surrounding the amount of allowances that Russia might be able to sell, the paper adopts a very conservative approach in estimating the benefit of allowances. More precise estimates and projections on the consequences of complying with the Kyoto Protocol will require a detailed general equilibrium model of the Russian economy to analyze the GDP - Energy $-\mathrm{CO}_{2}$ emissions nexus, and its sensitivity to policy reforms. 


\section{References}

Anisimov, O. 1997. "Permafrost Zonation and Climate Change in the Northern Hemisphere: Results from Transient General Circulation Models," Climatic Change 35 (2), 241-258.

Dudek, D., A. Golub, D. Marcellino, B. Muller, A. Petsonk, E. Strukova. 2004. "Economic Consequences of Possible Ratification of the Kyoto Protocol by the Russian Federation." Preliminary comments on the Institute for Economic Analysis paper, Environmental Defense, Center for Russian Environmental Policy: Moscow.

Ellerman D. and A. Decaux. 1998. "Analysis of Post-Kyoto CO2 Emissions Trading Using Marginal Abatement Curves," MIT Global Change Joint Program Report n40, MIT:Boston.

Golub, M., A. Avertchenkov. V. Berdin, A. Kokorin, M. Martynova, E. Strukova. 1999. Study on Russian National Strategy of Greenhouse Gas Emissions Reduction, World Bank: Moscow.

Government of Canada. 2001. Climate Change Plans for Canada.

Government of Russia. 2002. Russia Third National Communication to the UN Framework Convention on Climate Change.

Grubb, M. 2004. "Economics of Climate Change Mitigation. Presentation to a meeting on climate change," Russian Academy of Sciences, Moscow, 7 July.

Haites, Erik. 2004. "Estimating the CDM", PCFplus Research Report No 19, World Bank, Washington DC.

Heil, Mark T. and Thomas Selden. 2001. "Carbon Emissions and Economic Development: Future Trajectories Based on Historical Experience", Environment and Development Economics. 6 6383.

Holtsmark, Bjart and Ottar Maestad. 2002. "Emission Trading Under the Kyoto Protocol--Effects on Fossil Fuel Markets Under Alternative Regimes", Energy Policy. 30 207-218.

Holtsmark, Bjart. 2003. "Russian Behaviour in the Market for Permits Under the Kyoto Protocol", Climate Policy. 3 399-415.

Houghton, J.T., Ding, Y., Griggs, D.J., Noguer, M., van der Linden, P.J., Dai, X., Maskell, K., Johnson, C.A (Eds.). 2001. "Climate Change 2001: The Scientific Basis. Contribution of Working Group I to the Third Assessment Report of the Intergovernmental Panel on Climate Change." Cambridge University Press.

Institute of Economic Analysis (IEAr). 2004. Possible Ratification of the Kyoto Protocol by the Russian Federation and its Economic Implications. Moscow.

Institute of Energy Research of the Russian Academy of Science (InRU).S 2004.

International Energy Agency (IEA). 2002. World Energy Outlook 2002. OECD:Paris.

- 2003a. $\mathrm{CO}_{2}$ Emissions from Fossil-Fuel Consumption 1971-2001. OECD:Paris.

—. 2003b. World Energy Investment Outlook. OECD: Paris.

International Monetary Fund. 2004. "International Finance Statistics 2004”, IMF: Washington DC. 
Koch, Tobias and Axel Michaelowa. 1999. “'Hot Air' Reduction through non-Quantifiable Measures and Early JI," Joint Implementation Quarterly 5 (2), 9-10.

Mirrless-Black, J., N. Novcic, M. Grubb, A. Korppoo, and D. Newbery. 2004. Costs and benefits to the Russian Federation of the Kyoto Protocol. Report to the Department for Environment, Food and Rural Affairs, Cambridge Economic Policy Associates: Cambridge.

Moomaw, William and Gregory C. Unruh. 1997. "Are Environmental Kuznets Curves Misleading us? The Case of CO2 Emissions", Environment and Development Economics, 2 451463.

Ravallion, Martin et. al. 2000."Carbon Emissions and Income Inequality", Oxford Economic Papers. 52, 651-669.

Shvidenko A. and S. Nilsson. 2002. "Dynamics of Russian Forests and the Carbon Budget in 1961-1998: An Assessment Based on Long-Term Forest Inventory Data," Climatic Change $55(1), 5-37$.

U.S. DOE. 2004. International Emissions Outlook 2004, Washington DC.

UNFCCC. 2004. Russian Federation: Report on In-depth Review of the Third National Communication of the Russian Federation. FCCC/IDR.3/RUS. 7 June.

World Bank. 2001. "Indonesia: Environment and Natural Resource Management in a Time of Transition".

World Bank. 2004. “World Development Indicators 2004”, World Bank: Washington DC.

Yvonne Edwards

L:|Final Russia Kyoto.doc

November 8, 2004 6:52 PM 